\title{
ECONOMIC IMPACT OF ARTS EDUCATION IN COMMUNITY
}

\author{
${ }^{1}$ NIRUPA.S, ${ }^{2}$ DR.JANSIRANI
}

RESEARCH SCHOLAR , DEPARTMENT OF ECONOMICS ,VISTAS, PALLAVARAM, CHENNAI-117

\begin{abstract}
The open doors for a cutting edge kid or significantly more seasoned understudies to learn Although there are numerous conclusions about what is the issue here, it is additionally simple to see the numerous impacts of workmanship in individuals' regular daily existence. We could also ask what it is to be a person, as to ask what workmanship is ? Craftsmanship stimulatingly affects us, it stirs the faculties, it invigorates the mind, causes us to feel profound feelings and it makes us think in another manner. Workmanship has its impacts too on enthusiastic life as in the psychological and scholarly upgrade. A further meaning of craftsmanship may prompt an explanation that workmanship is accomplishments, items or exercises with which we attempt to alert others to similar encounters, sentiments and feelings that we have survived ourselves. This is normally done by utilizing the faculties to find the core interest. The faculties and tactile, eidetic or sense insight based encounters are in a vital situation to clarify the substance of craftsmanship. A person is constantly looking for a reaching surface to the real world and fact (so to state genuine world) through his own hands, by contacting and by doing assignments by hand. Workmanship is showing a reality in which the individual lives; it intercedes and supplies human encounters and simultaneously it sees the various parts of being a person. Workmanship and expertise subjects broaden the originations about the encompassing scene simultaneously as they offer good, tasteful and moral qualities through close to home encounters these qualities have diminished during that time at school just as in college level training. These qualities are absent in the perspective of numerous youngsters today, as we effectively can see from papers and other media. Some worldwide similar examination has demonstrated unmistakably that the completion educational system is succeeding astoundingly in instructing data
\end{abstract}

Key words:_Art education,economic development,community,schoolprogram

\section{ECONOMIC IMPACT OF ARTS EDUCATION IN COMMUNITY}

Workmanship schooling, human existence, expertise, improvement and so onWhile the majority of public school program and funding decisions are dictated by federal and state mandates the area in which local education and community leaders have enormous influence and decision making power is with extracurricular activities, such as sports, music and the arts. You can get a fairly good idea of what a local community values by examining how they allocate resources and what types of extracurricular activities are sponsored and emphasized in their schools.

The local public school environment and the values that are embraced and projected within that environment molds and influences the attitudes, beliefs and values of children, teachers, parents and general citizens of the community. What is taught and emphasized in schools influence and impact the culture and values of the community at large. Not only is that influence felt today, but many of those children eventually graduate and settle in the same community, bringing those attitudes and values to bear on the community for years to come. In other words, the values, priorities and culture of the local high school as reflected through the types of programs emphasized have a long lasting impact on the general values and culture of the community in which it is located.

One area in particular where programming can impact a community relates to economic development. Social scientist Richard Florida has conducted extensive research on the impact of arts and culture on economic development. In his groundbreaking work, The Rise of the Creative Class, he indentifies the emerging class of "creative professionals in business and finance, law, health care and related fields. These people engage in complex problem solving that involves a great deal of independent judgment and requires high levels of education or human capital. In addition, all members of the Creative Classwhether they are artists or engineers, musicians or computer scientists, writers or entrepreneurs-share a common creative ethos that values creativity, individuality, difference and merit. For the 
members of the Creative Class, every aspect and every manifestation of creativity-technological, cultural and economic-is interlinked and inseparable.

The Creative Class is the norm-setting class of our time. But its norms are very different: Individuality, self-expression and openness to difference are favored over the homogeneity conformity and "fitting in" that defined the organizational age.” (Florida, 2002, pp. 8,9)

According to Florida, this Creative Class can have a profound impact on economic development and a city or region's economic vitality. Members of the Creative Class are precisely the types of people civic leaders should work to attract to their communities to live, work and raise their families. Or, as summarized in an article that appeared in Economic Development "Because of their knowledge-based jobs, Florida asserts that members of the creative class tend to contribute directly to the growth of a thriving economy. Equally important, members of the creative class tend to prefer those jobs in geographical locations with high levels of culture and diversity. Florida thus argues that regions that support the arts will attract and retain the creative class and consequently enjoy higher levels of economic prosperity." (Lemore, et al., 2013, p. 222) It might appear to be a scope to think about monetary advancement of the nearby economy as a factor in deciding how to contribute a secondary school's extracurricular assets, however what is underscored at the secondary school level is consumed by understudies who at last alumni and become occupants of the town. What understudies are presented to and realize impacts what they will later an incentive as network ventures. It's difficult to envision that somebody who was not presented to a quality music and expressions educational plan as an understudy will esteem music and human expressions as a network venture as a grown-up.

Further, as indicated by Florida, individuals from the Creative Class will in general be more fruitful and occupied with the network. They are absolutely the kind of individuals a city, town or locale needs to draw in to their region to live, work and bring up their youngsters. The capacity for a city, town or locale to pull in such individuals is getting progressively significant as the Creative Class is made out of residents who are bound to be network "movers and shakers."

The test for networks comes from the way that individuals from the Creative Class have more opportunity to pick where they need to live. Such opportunity results from enhancements in transportation and correspondence (Internet, video conferencing, Skype, and so on) Before, when an organization moved to an alternate city or express, all workers were needed to get and move with the organization to the new area. Today, organizations are considerably more ready to offer adaptability to important "innovative" workers to stay with the organization while they live in another area. Similarly as the Creative Class incorporates the sorts of representatives that organizations worth and need to keep, they are additionally the kind of individuals a city, town or district should need to have in their locale as residents.

Along these lines, the inquiry becomes: What do networks have to bring to the table as assets and qualities that will speak to individuals from the Creative Class? As indicated by Florida, a significant, if not the major, network worth or highlight, is an imaginative, energetic, expressions arranged culture. Furthermore, one significant part of a particularly energetic expressions culture is the sort of responsibility the network makes to expressions of the human experience in the schools. Schools are regularly a significant choice influencer for individuals who are thinking about where to live, work and raise their families and individuals from the Creative Class specifically, are keen on the accentuation the neighborhood school locale puts on music and human expressions. Or on the other hand, expressed in an unexpected way, innovative individuals need to work with individuals and live in networks that esteem inventiveness. Also, on the grounds that music and human expressions are the most integral asset in our instructive and network arms stockpile to show inventiveness, it is basic that instructive and network pioneers consider that sway while apportioning instructive assets.

While imagination is the cash of things to come and a significant key to driving an energetic neighbourhood economy choices with respect to how a school puts resources into extracurricular exercises, for example, music, theater and visual 
expressions is massively significant as those choices and needs have both a prompt instructive effect on the understudies who take an interest in them, yet additionally a drawn out network financial improvement sway past the school dividers.

\section{Conclusion}

This outline gives a solid case to the advantages of dynamic commitment with expressions arranged all through the life expectancy. In youth there appear to be advantages for the advancement of perceptual abilities which impact learning language in this manner affecting on education which is additionally upgraded by occasions to create musical co-appointment. Fine engine coappointment is improved through figuring out how to play an instrument. Music additionally appears to improve spatial thinking, one part of general knowledge which is identified with a portion of the aptitudes needed in science. While general fulfillment is obviously influenced by education and numeracy abilities, inspiration which relies upon confidence, self-viability and yearnings is additionally significant in the measure of exertion given to considering. Commitment with music can improve self-insights yet just in the event that it gives positive learning encounters which are fulfilling. This implies that melodic encounters should be agreeable giving difficulties which are likewise feasible. Instructing needs to produce a climate which is steady and adequately adaptable to encourage the advancement of inventiveness and self-articulation. Gathering music making is additionally gainful to the advancement of social abilities and can add to wellbeing and prosperity all through the life expectancy and can in this way add to network union giving advantages to society all in all.

\section{References}

1. Altenmuller, E.O., Gruhn, W., Parlitz, D. et al. (1997) 'Music learning produces changes inbrain activation patterns: a longitudinal DC-EEG-study unit'. International Journal of ArtsMedicine, 5, 28-34.

2. Altenmuller, E.O. (2003). How many music centres are in the brain? In I. Peretz $\& \mathrm{R}$.
3. Zatorre (Eds.), The Cognitive Neuroscience of Music (pp 346-356). Oxford: Oxford University Press.

4. Anvari S.H., Trainor L.J., Woodside J. and Levy B.Z. (2002). Relations among musicalskills, phonological processing, and early reading ability in preschool children. Journal ofExperimental Child Psychology, 83, 111-130.

5. Anshel, M. and Marisi, D. (1978) Effect of music and rhythm on physical performance, Research Quarterly, 49, 10913.

6. Arnett-Gary, D. (1998) The effects of the arts on academic achievement. Masters Abstracts International, 42(01), 22. 